\title{
Understanding Bureaucracy: A Concept and Scale Development of Citizens' Administrative Literacy
}

Matthias Döring

mdoering@sam.sdu.dk

D) 0000-0002-5510-2579

Twitter: @mat_doering

University of Southern Denmark

Campusvej 55

DK-5230 Odense M

Denmark

\section{Author Bio}

Matthias Döring is Assistant Professor in Public Administration at the Department of Political Science and Public Management at the University of Southern Denmark. His research focuses on citizen-state interactions, street-level bureaucracy, service management, and digitalization. 


\title{
Understanding Bureaucracy: A Concept and Scale Development of Citizens' Administrative Literacy
}

\begin{abstract}
:
Administrative Literacy is the capacity to obtain, process, and understand basic information and services from public organizations needed to make appropriate decisions. Citizens' competencies necessary for successful interactions with public administration are an important resource that remains widely neglected. While interactions with public organizations impose a considerable administrative burden on citizens, that burden may differ quite significantly depending on their available resources to cope with such a burden. Research from other fields such as data or health literacy suggests that these concepts influence a variety of outcomes for both the individual and society. Such competence may change behavior and perception when interacting with public organizations, indicating its potential as an important factor influencing behavior such as compliance, and other outcomes. Citizens with high administrative literacy have a better understanding of procedures, structures, and rules. The article develops a concept and scale for measuring administrative literacy using data from a citizen survey.
\end{abstract}


Citizens encounter public organizations in various life situations, be it the police, the tax office or an office for social welfare. On these occasions, citizens interact (more or less) directly with the state and its administration. Yet, '[d]espite the critical importance of this link in public administration, citizen-state interactions have received relatively little direct attention within the field' (Jakobsen, James, Moynihan, \& Nabatchi, 2016, p. 1).

While the role of street-level bureaucrats (SLB) in such public encounters (Bartels, 2013; Goodsell, 1981) has been intensely researched over the last decades (Dubois, 2014; Keiser, 2010; Maynard-Moody \& Musheno, 2012), recently, public administration scholars have also looked at the relationship between SLB and citizens. Research on representative bureaucracy (Lim, 2006) has investigated the effect of ethnic (Hong, 2017), gender (Guul, 2018; Meier \& Nicholson-Crotty, 2006; Riccucci, van Ryzin, \& Li, 2016), and cultural matches between bureaucracies and citizens (Andersen, 2017). Furthermore, studies have examined the effects of the perceived deservingness of clients (Jilke \& Tummers, 2018), signals which are interpreted by SLB (Raaphorst \& van de Walle, 2018), causing discriminating behavior (Andersen \& Guul, 2019; Nicholson-Crotty, Nicholson-Crotty, \& Fernandez, 2017), or the role of trust between both participants in these encounters (Senghaas, Freier, \& Kupka, 2019). However, the role of citizens remains mostly passive in these studies, while scholars agree that the abilities and capacities of citizens may be crucial for influencing the behavior of SLB (Ludwig-Mayerhofer, Behrend, \& Sondermann, 2014; Senghaas et al., 2019, p. 10), e.g. during 
negotiation processes (Raaphorst \& Loyens, 2018, p. 22). While SLB will tend to treat most clients alike due to routinization, '[...] those who are particularly able to assist in managing their own cases, tend to receive differential responses [from the SLB]' (Lipsky, 2010, p. 122). To what extent are clients with different abilities and capacities able to convince the streetlevel bureaucrat to use his or her discretion in favor of the client? Are clients with a better understanding of rules and regulations more capable of avoiding sanctions? This interactional dimension of public encounters remains widely unexplored.

This study seeks to support a more citizen-centered perspective on interactions even further. Citizens will not only differ in terms of their attitudes and trust towards public institutions (Cook \& Gronke, 2005), but also in the way they interact due to their knowledge and skills (Gordon, 1975; Ludwig-Mayerhofer et al., 2014). By conceptualizing a model of 'administrative literacy' (AL), this study adds an explanation for differing behavior in public encounters.

This article is structured as follows: First, the role of individual competencies in public encounters will be explicated from a theoretical perspective. Second, the concept of administrative literacy will be developed. At that, the concept of health literacy will serve as a blueprint. Finally, further applications of administrative literacy to practice and other theoretical frameworks will be discussed. 


\section{The role of individual competencies in interactions with public organizations}

Interactions with public administrations have significant or even severe effects on citizens' everyday lives. Tax returns, applications for social welfare, day care - none of these interactions come without administrative burdens that shape the interactions' outcomes, citizens' perception, and behavior (Burden, Canon, Mayer, \& Moynihan, 2012). Administrative burden manifests in the form of costs that are imposed on the citizen. Moynihan et al. (2014) distinguish between three types of costs. Learning costs incur when citizens have to collect, process, and evaluate information about services and procedures. Which institution is responsible for my application? Am I eligible for the program? Which information is needed from me? The level of these learning costs, however, may differ among individuals who are more familiar with administrative organizations and specific vocabulary, or more skilled in searching for this information. Compliance costs describe the use of resources for following administrative requirements, rules, and procedures. The continuous reporting of family income for the application of welfare support is an example for such costs. Finally, psychological costs describe the loss of autonomy and the stigma of being dependent on programs that are negatively perceived. Herd and Moynihan (2018, p. 16ff) propose a comprehensive model of administrative burden in which they describe antecedents, 
consequences, and mediating factors. Accordingly, the impact of these costs will differ across different client groups (Herd \& Moynihan, 2018, p. 6f). Whether these costs will be easily handled, depends for example on the available human capital, such as skills, resources, and the client's network (Herd \& Moynihan, 2018, p. 30f). Moreover, Christensen et al. (2020) postulate the essential role of cognitive capacities to overcome burden, especially for vulnerable groups. Clients struggling with administrative processes may try to find (professional) help in the form of intermediaries (Döring \& Löbel, 2018) or NGO’s (Nisar, 2018) that help the individual to navigate the procedures.

Hence, administrative literacy represents one of the main categories of human capital, necessary to reduce administrative burden and lower the related costs. As such, it covers cognitive (e.g. reading) and noncognitive skills (e.g. patience) (Heckman \& Rubinstein, 2001; Heckman, Stixrud, \& Urzua, 2006) that affect the individual's human capital during interactions (Alan \& Ertac, 2018; Thiel \& Thomsen, 2013). Early studies show that "some personality traits will be more conducive than others to success in bureaucracies" (Gordon, 1975, p. 200).

Citizen-state interactions are special insofar as the context is often highly technical due to legal regulations underlying public services, the higher social status of state institutions, and the citizen's frequent dependence on decisions made by street-level bureaucrats (Lipsky, 2010). These conditions determine the behavior of the clients, as they require certain skills to 
cope with such situations. The study by Heinrich (2016) offers an analysis of administrative burden in the context of child support in South Africa. In her analysis, she confirms that finding required documents is one of the major factors explaining interrupted payments for an especially vulnerable group. Citizens falling short of these skills and knowledge may depend on third parties to help them by increasing their administrative literacy. In his study on a marginalized genderqueer group in Pakistan, Nisar (2018) finds that NGOs play an important role for members of these groups in supporting them with knowledge about administrative processes in order to empower them to overcome the administrative burden. These examples illustrate impressively the role of administrative literacy in easing the costs imposed by administrative burden. At the same time, these examples emphasize the impact of $\mathrm{AL}$ on social equity. Increasing the level of administrative literacy empowers citizens to access services and decisions for which they are eligible. At the same time, having these skills and knowledge at the individual's disposal empowers him or her to interact, even on such an unfamiliar turf as administrative processes.

Similar discussions have been held in public health research. For years, practitioners and scholars have rallied for empowering patients to increase their self-efficacy (Schwarzer, 2014; Strecher, DeVellis, Becker, \& Rosenstock, 1986). Under the concept of 'health literacy,' studies have investigated the effects of health-related knowledge and competences on patient 
compliance, number of visits to the doctor, and the perceived health (Baker, Parker, Williams, \& Clark, 1998; DeWalt, Berkman, Sheridan, Lohr, \& Pignone, 2004).

There is a wide debate on how to conceptualize and define health literacy (Sorensen et al., 2012). The most accepted approach is the 'skill-based' concept that builds on knowledge and its application (Kickbusch \& Maag, 2008). Accordingly, it is defined as 'the degree to which individuals have the capacity to obtain, process, and understand basic health information and services needed to make appropriate health decisions' (Selden, Zorn, Ratzan, \& Parker, 2000, p. ix). Within this skill-based perspective, Nutbeam (2000) identifies three dimensions that make up health literacy: functional, communicative/interactive and critical literacy. While functional literacy describes general reading and writing abilities (Baker et al., 1998), the latter two dimensions push the concept beyond mere information accumulation: A patient with high health literacy is able to read and understand more technical texts (such as drug descriptions). Additionally, the patient is also able to critically reflect on the information and express concerns to the doctor, ask questions and communicate at an eye level despite the typical information hierarchy of doctor-patient relationships (Nutbeam, 2009; PaascheOrlow \& Wolf, 2007). 
Manganello (2008) extends this concept with a dimension of media literacy due to the increasing importance of provision and selection of information in a mass media setting. The availability of such media enables clients to become increasingly autonomous while also overloading them with information. This potential overload again demands a critical evaluation of the information and its sources (Knibbe, Vries, \& Horstman, 2016). Freedman et al. (2009) shift the concept from an individual level to a macro-level, conceptualizing the effects of public health literacy on complex social structures such as societies. By adding a civic orientation, they want to sensitize researchers to the societal implications of healthrelated decisions and behavior on the individual level (e.g. vaccination). Zarcadoolas (2005) follows a different approach, creating an analytical framework in which to evaluate the actions of policy actors concerning their communication of health-related issues. Beside functional literacy, she differentiates between science literacy, civic literacy, and cultural literacy. Science literacy constitutes the general knowledge and understanding of science, such as expressions of probabilities and relations (e.g. rates of contagion) and the ability to evaluate those. Civic literacy again resembles the approach by Freedman et al. (2009) in describing an understanding of complex interactions between the individual and society. Finally, cultural literacy emphasizes the relevance of social identities and symbols when communicating about health-related information. 
The interaction between doctor and patient is characterized by an information asymmetry that constitutes the basis of a relationship of dependency in which trust is of special importance. These characteristics resemble those of public encounters, as well as the interaction between SLB and citizens.

Another increasingly important concept that has been widely neglected in the debate on health literacy is the role and mastery of digital resources and tools. Digital literacy (Gilster, 1997) is a comparably recent concept discussed since the advent of the digital age. While it shows certain overlapping ideas with media literacy in the sense of a (critical) assessment of information from various sources, it also emphasizes the specific differences with digital tools and the presentation of information in that setting. Thus, reading and understanding nonsequential and dynamic material that comes in different medial formats, mastery of specific hard- and software, and the willingness and ability to publish and/or communicate information are specific challenges of the digital realm distinct from traditional channels of interactions (Bawden, 2001). With the progressive introduction of apps and online processing, digital channels become a new default with which public administration provides information or even the service as a whole. Hence, citizens are expected to possess sufficient levels of digital literacy to use these emerging channels. 


\section{A concept of administrative literacy}

Taking the conception of health literacy and the given approaches defining administrative literacy as a basis, this article conceptualizes a multidimensional model of administrative literacy. For this purpose, seven sub-categories of administrative literacy will be formed: functional literacy, communicative literacy, structural literacy, processual literacy, civic literacy, media literacy, and digital literacy. These dimensions are based and derived from similar sub-dimensions in the health literacy literature, while adding domain-specific dimensions on characteristics of administrative structures and processes (Grönlund, Hatakka, \& Ask, 2007).

Functional literacy describes the basic capability to understand specific bureaucratic language. Therefore, it represents the basis for an understanding of administrative work procedures, writings and requests. Redish (1983) describes bureaucratic language as characterized by a specific technical vocabulary and longer and more complex sentence constructions (in particular, passive constructions). This complex and elaborate language is rooted in a judicial working structure and a depersonalized work manner (Sarangi \& Slembrouck, 1996). 
Therefore, a certain level of functional literacy is necessary for acquiring and exchanging information.

Communicative literacy builds on the basic skills of functional literacy by describing the ability to interact and communicate with others. This ability includes oral and written expression, actively listening to others, and discussing opinions. Especially in encounters in which the SLB have discretion, expressing one's concerns, persuading the counterparts, and objecting to decisions are crucial for citizens. Raaphorst and Loyens (2018) show that negotiations can be a major mechanism in citizen-state encounters. Thus, being able to perform well, playing the right role by choosing the right arguments in different situations can be crucial for convincing street-level bureaucrats.

Structural literacy includes a comprehension of internal and external administrative structures. In particular, it gives insight into the general working and organizational structures of public organizations. The citizen understands organizations not just as a black box. Furthermore, the citizen is able to find the organizational unit relevant for his or her concerns in a broader bureaucratic system. This may turn out to be crucial in cases in which the client needs to find the right contact person for applications, complaints, or objections. It may also 
foster an understanding of the structure of work in public organizations and its effects on procedures.

[Table 1 here]

Knowledge about bureaucratic working procedures and the expected forms of interaction with public organizations is described under processual literacy. This is expressed mainly in an impersonal use of communication and a focus on routines (Lipsky, 2010, p. 99f). In order to successfully complete especially long-term administrative processes with multiple episodes, citizens often need patience and conscientiousness during interactions in order to achieve positive outcomes. This knowledge and the respective expected behavior may be crucial for appropriate interactions with SLB.

Similar to the health care field, administrative action has a societal regulatory character. Civic literacy illustrates the capability of individuals to deduce the relevance of one's actions for society as a whole. For the individual, the purpose of certain regulations and obligations may not always be comprehensible, as they aim for a higher purpose for wider segments of society. Whether regulations are opposed as red tape (Bozeman \& Feeney, 2011; DeHart-Davis, Davis, \& Mohr, 2015) or understood as justified may depend on that subjective perception. 
Media literacy is understood as the capacity to process, understand, and critically evaluate information from mass media such as television and the Internet. Media as a source of information is relevant for administrative literacy for different reasons: On the one hand, it influences communication between the political-administrative system and the citizens (Dahlgren, 2005), e.g. whether the citizen learns about new policies (such as new social programs) and whether he or she is able to judge his or her eligibility. On the other hand, a critical assessment of information gathered from various sources allows validation of its credibility. Internet sources play an increasing role when interacting with public organizations (Reddick \& Turner, 2012), e.g. to find forms, but also to get advice from other citizens in forums or social media.

Finally, and rather complementary to media literacy, digital literacy supplements the general concept. Bawden (2008) summarizes four components that constitute digital literacy. The general underpinnings, background knowledge, central competencies, as well as attitudes and perspectives. While functional literacy, the critical assessment of information, and a social and societal understanding of one's actions are already covered by the other sub-dimensions, the addition of digital literacy focusses on the mastery of ICT tools - both hard- and software the specific processing of information in digital formats compared to traditional media, and 
the creation and communication of digital information. Grönlund et al. (2007) find that digital services lower the general knowledge and skill requirements for applicants. However, especially complicated services may cause additional burden and the need for skills to search information online and technological literacy.

As administrative literacy is described here as a skill-based concept, the individual's level is variable and not fixed. Experience from prior public encounters, information gathered from other sources, advice given by peers - all these aspects may increase (or potentially decrease) administrative literacy.

In general, AL is conceptualized as a universal set of skills and knowledge, applicable to a wide range of policy fields. However, it is primarily focused on formal public encounters that result in either status-changing decisions based on discretion or formal service encounters such as consultation for unemployed. Other more informal interactions that mainly provide a service function (think of parents interacting with teachers concerning their children's grades) may not necessarily be influenced by the AL level of the parents. Nevertheless, such formal encounters are also common in the education sector when parents apply for second- 
tier schools, exemptions from sports classes (e.g. for religious reasons) and other statuschanging decisions.

\section{The effects of administrative literacy}

The effects of high AL are expected to be manifold (see Figure 1). On the individual level, all three types of costs related to administrative burden are addressed. Higher capacities are expected to lower learning costs as clients find it easier to gather and process necessary information from various information sources, such as information pages on the internet or directly from forms. Furthermore, compliance costs should be lowered as clients interact and contribute to the service in the 'expected way'. Clients would find it easier to comprehend forms and communicate with their agents on the different matters. Moreover, they could be able to take a stronger stance in negotiation processes to lower expected documentation needs (Raaphorst \& Loyens, 2018).

Higher levels of administrative literacy may also cause psychological empowerment, increasing self-perceived efficacy when interacting with official institutions (Kristensen, Andersen, \& Pedersen, 2012; Paasche-Orlow \& Wolf, 2007). Thereby, the psychological costs 
may be cushioned. This may increase the propensity of citizens to actively engage in voice behavior when dissatisfied with public services (Hirschman, 1970; Wallin Andreassen, 1994). It could, for example, explain why some citizens tend to participate in citizen surveys or panels (Crosby, Kelly, \& Schaefer, 1986), or get involved in citizen participation processes (Bingham, Nabatchi, \& O’Leary, 2005; Kathlene \& Martin, 1991; Weber, Loumakis, \& Bergman, 2003). Furthermore, it could prove to be a major antecedent for co-production behavior (Parrado, van Ryzin, Bovaird, \& Löffler, 2013; van Eijk \& Steen, 2016). Greater familiarity with administrative vocabulary as well as one's own rights and duties when interacting with public organizations may also influence the citizen's chances for successful applications. By knowing important key words or shortcuts in the administrative process, he or she may seize opportunities that citizens with lower administrative literacy may not be aware of. The empowerment may also have implications on the overall evaluation of public services. Studies on satisfaction with services in the private sector indicate that greater empowerment and self-efficacy of clients increase their satisfaction with services, positive word-of-mouth, and customer loyalty (Dong, Evans, \& Zou, 2008; Fuchs \& Schreier, 2011; Soss, 1999; Tiu Wright, Ouschan, Sweeney, \& Johnson, 2006).

[Figure 1 here] 
On the interactional level, citizens with higher administrative literacy may lower the transaction costs for SLB, as they require less consultation, make fewer mistakes when filling out forms and may be generally better informed. Furthermore, it may also be possible that such citizens behave differently when interacting with SLB. Courtesy and respectfulness, but also deliberately used communication strategies (Kasper \& Kellerman, 2014), may influence the behavior of the SLB who will make the decisions.

On the societal level, higher administrative literacy may be associated with higher levels of trust in public institutions. As people understand the nature of bureaucratic organization (and their rationality), public organizations may lose their Kafkaesque aura which often creates prejudice and skepticism about their legitimacy. Likewise, AL may be an important factor for the outreach of certain policies such as social programs. In order to be effective, such policy programs need to actually reach the supposed target groups in need. Oftentimes, however, missing knowledge of the existence of such services, one's potential eligibility or access barriers may lower the demand (Cortis, 2012). Thus, differences in AL may explain why programs that are generally open to a broad audience are harnessed by a mere fraction causing greater inequality. Finally, higher administrative literacy may lower the societal costs for unjustified complaints and lawsuits that burden courts. 
While the suggested effects may be substantive, citizens remain in an asymmetrical relationship with public organizations. No matter how high the administrative literacy of an individual may be, decisions based on discretion will be made by street-level bureaucrats. Higher AL levels will not create privileges but may help to create more privileged outcomes compared to other citizens.

The concept of administrative literacy is closely related while still distinct to other concepts such as self-efficacy. Cognitive theories conceptualize self-efficacy as the prior assessment of perceived effectiveness when encountering a specific situation (Bandura, 1977). However, this expectation of one's efficacy is complemented by the capabilities and skills that the individual has at their disposal (Caprara, Vecchione, Capanna, \& Mebane, 2009). As such, it cannot be taught, but with increasing mastery of certain tasks it will increase as a cognitive learning process. Thus, administrative literacy represents the capabilities, skills, and knowledge needed when interacting with public administrations. Higher levels of AL, however, will likely increase one's perceived efficacy when having experiences of mastery. Administrative literacy is therefore an addition to understanding citizen-state interactions connected to such concepts as public service efficacy (Kristensen et al., 2012). The effect of these necessary skills and knowledge will be mediated by self-efficacy into a more proficient performance (Ozer \& Bandura, 1990, p. 473). 
This also leads to the possible adverse effects of administrative literacy. Citizens with higher levels may be more capable of 'gaming the system,' as they are aware of administrative (inefficient) processes and are more willing to take risks, e.g. when not giving sufficient or necessary information in application processes. Additionally, higher levels could increase a citizen's self-efficacy, which in turn increases the likelihood voicing dissatisfaction with a decision made by the public organization, thus boosting transaction costs. Accordingly, clients with higher AL may be more likely to articulate shortcomings, also due to their communicative skills.

Furthermore, a broader understanding of a complex and even onerous administrative system may engender skepticism about flaws and inefficiencies within. Moreover, street-level bureaucrats may enact cherry-picking individuals with higher levels of AL as they are "easy cases" that are capable of managing themselves (Lipsky, 2010, p. 122).

In general, differences in individual literacy skills should not be used as an excuse for governmental inaction to overcome inequalities caused by low administrative literacy. Rather, governments should see this concept as a tool to specifically address administrative burden.

\section{Measuring administrative literacy}


Gordon (1975) proposed a first attempt at measuring administrative competence. She used a mixture of survey, ethnographic, and quiz-based measures. This included a question about who filled out the person's tax form, a quiz about bureaucratic vocabulary, and an assessment of the comprehension of vocabulary during an interaction with caseworkers. While this triangulated measurement has its clear benefits in preventing common-method bias, it suffers from low statistical power (Gordon only measured about 60 individuals) due to its costly measurement. Furthermore, there might be concerns with the reliability of the measurement. The conceptualization of administrative competence also remains rather narrow by focusing mostly on functional literacy. Additionally, measurement instruments aimed at such issues need to manage the balance between the specificity of certain administrative fields (such as policing or social services) and general skills that are as widely usable as possible.

A vast landscape of different measurement tools has evolved in the field of health literacy (Haun, Valerio, McCormack, Sørensen, \& Paasche-Orlow, 2014). Most of them are related to the Rapid Estimate of Adult Literacy in Medicine (REALM) or the Test of Functional Health Literacy for Adults (TOFHLA), which serve as gold standards for objective measurement concerning health literacy. However, there is also a variety of self-assessed survey tools. One major advantage of such self-assessments is their efficiency in large- $n$ studies. Despite that advantage, potential self-report bias is a commonly expressed critique 
of such instruments, as individuals tend to over-exaggerate their competence levels. However, this generic approach to measurement comes with the advantage of broad applicability. More objective measures such as quizzes need to be specific for certain types of services. In this regard, we would need to measure the administrative literacy levels for child support differently than applications for pensions. Moreover, those measures are costlier to implement - e.g. in a survey study - compared to self-assessments.

In order to develop the concept of administrative literacy with its assumed sub-dimensions, this study follows a quantitative approach of scale development (DeVellis, 2017). The data used here was collected in November 2017 via an online survey among participants $(n=1.090)$ of a German consumer panel. This sample was chosen randomly while being stratified in terms of age, education, and gender to mirror similar distributions in the general German population. First, an item pool was created building on the above-described sub-dimensions of administrative literacy, resulting in a scale of 27 items. The item formulation is based on various survey measure for health literacy while adjusting for the public sector specific demands while following best practice recommendations (DeVellis, 2017). Thus, complex formulations, words, and double negatives were avoided. Overall, most items are based on the Health Literacy Questionnaire (Osborne, Batterham, Elsworth, Hawkins, \& Buchbinder, 2013), namely communicative, structural, and media literacy. Functional literacy is based on 
the general comprehension of health-related information as conceptualized by Chew et al. (2004), however the items differentiate between the specific demands of bureaucratic language (Sarangi \& Slembrouck, 1996). The dimensions of process literacy are based on characteristics of bureaucratic processing (Lipsky, 2010; Sarangi \& Slembrouck, 1996).

All items were measured on a 5-point Likert scale. The item pool was then reviewed and revised in a pretest with 20 participants to evaluate face validity. To conduct factor analyses and post-tests, the author used the statistical program R and the packages 'lavaan' (Rossel, 2017), 'psych' (Revelle, 2017), and 'semTools' (Pornprasertmanit, Miller, Schoemann, \& Rosseel, 2016).

For internal replication (J. W. Osborne \& Fitzpatrick, 2012), the sample was randomly split in half $(\mathrm{n} 1=547, \mathrm{n} 2=543)$. While $\mathrm{n} 1$ was used to calculate the exploratory factor analysis (EFA), the established factor structure was tested using confirmatory factor analysis (CFA) on sub-sample n2.

\section{Exploratory \& Confirmatory Analysis}

In a first step, the pool of 27 items composing the theoretically proposed 6 dimensions of administrative literacy was introduced into an exploratory factor analysis to investigate the data structure. The measure of sample adequacy (overall MSA=0.86) as well as the Bartlett test $(\chi 2(\mathrm{df} 351)=6996.958 ; \mathrm{p}<0.001)$ (Dziuban \& Shirkey, 1974) suggest an appropriate 
sample and matrix structure. Using parallel analysis (Horn, 1965), the items load into preferably 7 factors. Oblique rotation was used, since it is very likely that the sub-dimensions are correlated. Table 6 shows the loadings of the 27 items. A total of 10 items were omitted afterwards. Of these, eight items were removed due to low factor loadings $(<.4)$ or substantial cross loadings. An additional two items were dropped for reasons of theoretical consistency in the different dimensions. With the remaining 17 items (item descriptions can be found in Table 8), the EFA was repeated. As can be seen in Figure 2, parallel analysis suggests a 5factor model. The loadings for this revised model are described in Table 7. The EFA shows five distinct factors: 1) communicative literacy, 2) processual literacy, 3) structural literacy, 4) functional literacy, and 5) media literacy. The factor loadings are satisfying and well above 0.5 ; there are no substantial cross-loadings.

Unfortunately, the measure for civic literacy did work in the intended way. The awareness of one's interaction with the state in a societal context seems to be unrelated to the general competences and skills necessary to do so. The omission of this dimension, however, leads to no misfit with the general definition provided in this paper. Nevertheless, other related concepts, such as altruism or citizenship behavior, may still provide fruitful insights on the relationship between AL and outcome variables in future research.

In a next step, the second sample was analyzed to recreate the factor structure with sample n2 using a CFA. The first model achieved a satisfying fit with $\chi 2($ df 109$)=353.222 ; \mathrm{p}<$ 
0.001; CFI $=0.941 ;$ RMSEA $=0.067(90 \%$ CI: $0.059-0.075) ;$ SRMR $=0.055(\mathrm{Hu} \&$ Bentler, 1999). The internal consistency reliability of the first model is good, with an overall McDonald's omega $\omega$ of 0.92 . The single sub-dimensions range from 0.75 (satisfying) to 0.92 (good) (see Table 8). McDonald's omega is more adequate than the commonly used Cronbach's alpha, as it accounts for different weights of sub-dimensions and items affecting the first-level dimension, while Cronbach's alpha builds on equal weights.

When analyzing the modification indices, particularly two pairs of items (PA2(1) PA2(2), PA2(3) PA2(4)) decrease the goodness of fit, both belonging to the sub- dimension of processual literacy. While the first two items refer to typical behavior of organizations themselves, the latter two are focused on behavior that clients adopt. Therefore, in a second model, an additional correlation between these pairs was specified to account for the similarities. This second model achieved an even better fit, with $\chi 2(\mathrm{df} 107)=282.205 ; \mathrm{p}<$ 0.001; CFI $=0.958 ;$ RMSEA $=0.057(90 \%$ CI: $0.049-0.065) ; \mathrm{SRMR}=0.052$.

In order to test the parsimony of the previous first-order model, a second- order model with a latent factor combining the different dimensions was modeled. Therefore, the goodness of fit as well as the log-likelihood-based Akaike and Bayesian information criteria were compared (see Table 2). For the latter, the model is preferred that achieves lower AIC and 
BIC (Vrieze, 2012). All estimated criteria indicate that the first-order model is to be preferred. However, the differences in AIC and BIC are rather small.

[Table 2 here]

To evaluate the validity of the construct, further tests were conducted. The internal construct validity can be assessed by the inter-dimensional correlations. The different sub-dimensions should not correlate in the different directions as they measure a common construct. The correlations should not be too high, however, as the latent variables need to be distinguishable. Table 3 shows that the correlations range from $r=-0.085$ to $r=0.431$, indicating that the constructs are heterogeneously related to each other. This is not surprising, since the different dimensions reflect a wide range of competencies that are not necessarily congruent. However, there are no significant contrary correlations.

[Table 3 here]

The assessment of convergent construct validity adds to the evaluation of construct validity, as it shows the theoretically assumed effects on other factors (Campbell, 1960). As the different dimensions are not congruent, the author expects that the investigated relationships 
will not necessarily be determined the same way by every sub-dimension. Each sub-dimension may play a major role when investigating different antecedents or dependent variables. As proposed in the theoretical explanations, the effects on self-assessed self-efficacy when interacting with public organizations, the ease of speaking with administrative staff, and the compliance with deadlines given by public organizations were assessed. Table 4 shows the results of a comprehensive structured equation model (SEM) which underline that the different dimensions of AL have specific effects on several outcome variables, such as selfefficacy, compliance with deadlines, and overall satisfaction. The results also confirm the expected ambivalent effects that administrative literacy may cause, as higher process literacy - and thus an understanding of procedural rules - increases frustration.

[Table 4 here]

Finally, in order to assess the discriminant validity, the average variance extracted (AVE) is compared to the squared inter-construct correlation (Fornell \& Larcker, 1981). The subdimensions have a high AVE $>0.6$, except for processual literacy which only achieves an AVE of 0.43 (see Table 8). However, compared to the squared inter-construct correlation, each dimension achieves satisfactory discriminant validity. Additionally, Table 4 shows that the measured construct is unrelated to other constructs from which it should theoretically 
differ. The investigated constructs are gender and education, as well as whether the citizen works in the public or private sector. The results show that neither of these variables is correlated with the sub-dimensions of administrative literacy. Education seems to be, as argued above, somewhat uncorrelated with administrative literacy in general, except for functional literacy as a basic skill mostly developed in school. This in line with research on health literacy pointing to the importance of education and socioeconomic status on functional and communicative literacy (Furuya, Kondo, Yamagata, \& Hashimoto, 2015; Mancuso, 2010; Rikard, Thompson, McKinney, \& Beauchamp, 2016). However, researchers have argued that these factors have only a limited relevance for other dimensions of the health literacy concept (Zarcadoolas, 2005) and find that literacy provides additional explanation of variance than merely relying on education (Howard, Sentell, \& Gazmararian, 2006). Transferred to AL, this explains why people struggle to interact with public organizations despite having, for example, college degrees.

\section{Limitations and Future Research}

The limitations of this study need further discussion. The measurement strategy used in this paper is based solely on perceptual and self-assessed ratings. While this strategy offers a broad usability and convenient form of measurement, it also comes with substantial drawbacks. As 
discussed with other empirically measured concepts such as quality (Cheon, Song, Mccrea, \& Meier, 2019), self-assessed perception-based measures may be distorted by other factors such as perception bias and misperception. This could cause people to both over- and underestimate their abilities in this measure. In this study, unfortunately, no other measurements (such as quizzes) were available for comparison. Accordingly, future research should validate this scale by comparing it with more objective measures on specific subfields. Furthermore, survey instruments in general fail to cover clients with severe language deficiencies. Thus, the most vulnerable may not be detected using this methodology.

Hence, other methodological approaches may complement research on administrative literacy, like ethnological approaches (Hand \& Catlaw, 2019). Additionally, it would be interesting to compare this measure with the assessment made by others, explicitly streetlevel bureaucrats. This could be especially important for research on public encounters. Are SLB able to assess the literacy level of their clients? How does it change their behavior? Will it trigger more facilitative behavior (Boer, 2018), or could it lead to cream-skimming behavior, prioritizing those cases with expectedly lower transaction costs?

However, this generic approach to measurement comes with the advantage of broad applicability. More objective measures such as quizzes need to be specific for certain types of services. In this regard, we would need to measure the administrative literacy levels for child support differently than applications for pensions. Moreover, these measures would be 
costlier to implement than the approach presented here. Furthermore, replications of the factor structure are needed to assess the reliability of the scale.

Furthermore, the nature of the sample may confine the results' representativeness. Although the sample is stratified with regard to population characteristics (age, education, and gender), online panel surveys may exclude specific subgroups from the recruitment process, especially those that lack basic technological or language skills. The measure for socioeconomic status used in this study was only limited and did not contain income data. Future studies should take these factors into account to differentiate between general socioeconomic effects and additional explanatory power of administrative literacy.

Future research should also investigate the relationship to related concept. As the digital transformation of public services progresses constantly, the need for additional skills to interact with public organizations may arise. Grönlund et al. (2007) find that digital services lower the general knowledge and skill requirements for applicants. However, especially complicated services may cause additional burden and the need for skills to search information online and technological literacy. While the sub-dimension media literacy captures the first, the latter may be essential specifically in countries with ubiquitous digital government services (Chen, Chen, Ching, \& Huang, 2007). 


\section{Conclusion}

Citizens interact with different kinds of public organizations on a fairly regular basis. Understanding the dynamics of these interactions is key to shaping it into an encounter that benefits both sides of the interaction. The awareness that citizens bring different competencies is important for managing the client relationship, e.g. when designing processes or application forms and training staff in communication (Bell, Auh, \& Smalley, 2005).

The construct of administrative literacy captures these different competencies. It determines whether citizens can communicate on at eye level. Since a lot of decisions by street-level bureaucrats are affect by the appearance and behavior of citizens in public encounters (Andersen, 2017; Jilke \& Tummers, 2018; Maynard-Moody \& Musheno, 2012), this factor may be crucial for understanding the use of discretion. Citizens' administrative literacy may also influence their knowledge about policies and their eligibility for social programs or the results of negotiations with public employees. At the same time, public employees may take advantage of the lower transaction costs due to fewer mistakes or questions from the clients, as well as their higher level of compliance with information delivery and deadlines.

Future research on the citizen-state interaction may benefit from this analytical tool. Concepts such as public self-efficacy, psychological costs, trust in institutions, and compliance, as well 
as political involvement and co-production, may benefit from the added perspective of citizens' skills and knowledge concerning the administrative system and processes. At the same time, administrative literacy may also be a factor explaining gaming behavior on both sides, that of citizens as well as SLB. Administrative literacy may serve as a useful tool in several methodological settings ranging from ethnographic and qualitative studies to, of course, quantitative surveys. Tools to improve administrative literacy may be tested in experimental settings. This could prove especially useful for practitioners and policy makers. Knowing the level of administrative literacy of their clients could improve the work of public employees, as they can address citizens more adequately. At the same time, as the concept of administrative literacy is skill-based, the SLB-client nexus could also be one of the major sources of improvement in the citizen's understanding when the SLB invest time to explain different procedures, for example. Therefore, it could also be useful to develop an objective measure of administrative literacy in order to accurately assess individual literacy in long-term service rapports. Policy makers could adjust their communication strategies to be more sensitive to differences in administrative literacy. 


\section{References}

Alan, S., \& Ertac, S. (2018). Fostering patience in the classroom: Results from randomized educational intervention. Journal of Political Economy, 126, 18651911.

Andersen, S. C. (2017). From Passive to Active Representation-Experimental Evidence on the Role of Normative Values in Shaping White and Minority Bureaucrats' Policy Attitudes.

Andersen, S. C., \& Guul, T. S. (2019). Reducing Minority Discrimination at the Front Line-Combined Survey and Field Experimental Evidence.

Baker, D. W., Parker, R. M., Williams, M. V., \& Clark, W. S. (1998). Health literacy and the risk of hospital admission.

Bandura, A. (1977). Self-efficacy: Toward a unifying theory of behavioral change.

Bartels, K. P. R. (2013). Public Encounters: The history and future of face-to-face contact between public professionals and citizens.

Bawden, D. (2001). Information and digital literacies: A review of concepts. Journal of Documentation, 57, 218-259.

Bawden, D. (2008). Origins and Concepts of Digital Literacy. In New Literacies and Digital Epistemologies: Vol. 30. Digital literacies: Concepts, policies and practices. New York: Peter Lang.

Bell, S. J., Auh, S., \& Smalley, K. (2005). Customer Relationship Dynamics: Service Quality and Customer Loyalty in the Context of Varying Levels of Customer Expertise and Switching Costs.

Bingham, L. B., Nabatchi, T., \& O'Leary, R. (2005). The New Governance: Practices and Processes for Stakeholder and Citizen Participation in the Work of Government. 
Boer, N. (2018). Street-level Enforcement Style: A Multidimensional Measurement Instrument.

Bozeman, B., \& Feeney, M. K. (2011). Rules and Red Tape: A Prism for Public Administration Theory and Research. Armonk, New York: M.E. Sharpe, Inc.

Burden, B. C., Canon, D. T., Mayer, K. R., \& Moynihan, D. P. (2012). The Effect of Administrative Burden on Bureaucratic Perception of Policies: Evidence from Election Administration.

Campbell, D. T. (1960). Recommendations for APA test standards regarding construct, trait, or discriminant validity.

Caprara, G. V., Vecchione, M., Capanna, C., \& Mebane, M. (2009). Perceived political self-efficacy: Theory, assessment, and applications.

Chen, Y., Chen, H. M., Ching, R. K. H., \& Huang, W. W. (2007). Electronic Government Implementation: A Comparison between Developed and Developing Countries. International Journal of Electronic Government Research, 3, 45-61.

Cheon, O., Song, M., Mccrea, A. M., \& Meier, K. J. (2019). Health Care in America: The Relationship Between Subjective and Objective Assessments of Hospitals.

Chew, L. D., Bradley, K. A., \& Boyko, E. J. (2004). Brief questions to identify patients with inadequate health literacy. Health, 11, 12.

Christensen, J., Aarøe, L., Baekgaard, M., Herd, P., \& Moynihan, D. P. (2020). Human Capital and Administrative Burden: The Role of Cognitive Resources in CitizenState Interactions. Public Administration Review, 80, 127-136.

Cook, T. E., \& Gronke, P. (2005). The Skeptical American: Revisiting the Meanings of Trust in Government and Confidence in Institutions.

Cortis, N. (2012). Overlooked and under-served?: Promoting service use and engagement among 'hard-to-reach' populations. 
Crosby, N., Kelly, J. M., \& Schaefer, P. (1986). Citizens Panels: A New Approach to Citizen Participation.

Dahlgren, P. (2005). The Internet, Public Spheres, and Political Communication: Dispersion and Deliberation.

DeHart-Davis, L., Davis, R. S., \& Mohr, Z. (2015). Green Tape and Job Satisfaction: Can Organizational Rules Make Employees Happy?

DeVellis, R. F. (2017). Scale development: Theory and applications. Los Angeles; London; New Delhi; Singapore; Washington DC; Melbourne: Sage.

DeWalt, D. A., Berkman, N. D., Sheridan, S., Lohr, K. N., \& Pignone, M. P. (2004). Literacy and health outcomes: A systematic review of the literature.

Dong, B., Evans, K. R., \& Zou, S. (2008). The effects of customer participation in cocreated service recovery.

Döring, M., \& Löbel, S. (2018). Street-Level Bureaucrats und Intermediäre: Beziehung auf Augenhöhe?

Dubois, V. (2014). The State, Legal Rigor, and the Poor: The Daily Practice of Welfare Control.

Dziuban, C. D., \& Shirkey, E. C. (1974). When is a correlation matrix appropriate for factor analysis?: Some decision rules.

Fornell, C., \& Larcker, D. F. (1981). Evaluating Structural Equation Models with Unobservable Variables and Measurement Error.

Freedman, D. A., Bess, K. D., Tucker, H. A., Boyd, D. L., Tuchman, A. M., \& Wallston, K. A. (2009). Public Health Literacy Defined.

Fuchs, C., \& Schreier, M. (2011). Customer Empowerment in New Product Development*. 
Furuya, Y., Kondo, N., Yamagata, Z., \& Hashimoto, H. (2015). Health literacy, socioeconomic status and self-rated health in Japan. Health Promotion International, 30, 505-513.

Gilster, P. (1997). Digital literacy. New York, NY: Wiley.

Goodsell, C. T. (Ed.). (1981). The Public encounter: Where state and citizen meet. Bloomington: Indiana University Press.

Gordon, L. K. (1975). Bureaucratic Competence and Success in Dealing with Public Bureaucracies.

Grönlund, Å., Hatakka, M., \& Ask, A. (2007). Inclusion in the E-Service Society Investigating Administrative Literacy Requirements for Using E-Services (M. A. Wimmer, Ed.). Berlin [u.a.]: Springer.

Guul, T. S. (2018). The Individual-Level Effect of Gender Matching in Representative Bureaucracy.

Hand, L. C., \& Catlaw, T. J. (2019). Accomplishing the Public Encounter: A Case for Ethnomethodology in Public Administration Research.

Haun, J. N., Valerio, M. A., McCormack, L. A., Sørensen, K., \& Paasche-Orlow, M. K. (2014). Health literacy measurement: An inventory and descriptive summary of 51 instruments.

Heckman, J. J., \& Rubinstein, Y. (2001). The importance of noncognitive skills: Lessons from the GED testing program. American Economic Review, 91, 145-149.

Heckman, J. J., Stixrud, J., \& Urzua, S. (2006). The effects of cognitive and noncognitive abilities on labor market outcomes and social behavior. Journal of Labor Economics, 24, 411-482.

Heinrich, C. J. (2016). The Bite of Administrative Burden: A Theoretical and Empirical Investigation. 
Herd, P., \& Moynihan, D. P. (2018). Administrative Burden: Policymaking by Other Means. Chicago: Russell Sage Foundation.

Hirschman, A. O. (1970). Exit, voice, and loyalty: Responses to decline in firms, organizations, and states. Cambridge, Mass.: Harvard Univ. Press.

Hong, S. (2017). Does Increasing Ethnic Representativeness Reduce Police Misconduct?

Horn, J. L. (1965). A rationale and test for the number of factors in factor analysis.

Howard, D. H., Sentell, T., \& Gazmararian, J. A. (2006). Impact of health literacy on socioeconomic and racial differences in health in an elderly population. Journal of General Internal Medicine, 21, 857-861.

Hu, L., \& Bentler, P. M. (1999). Cutoff criteria for fit indexes in covariance structure analysis: Conventional criteria versus new alternatives.

Jakobsen, M., James, O., Moynihan, D., \& Nabatchi, T. (2016). JPART Virtual Issue on Citizen-State Interactions in Public Administration Research.

Jilke, S., \& Tummers, L. (2018). Which Clients are Deserving of Help?: A Theoretical Model and Experimental Test.

Kasper, G., \& Kellerman, E. (2014). Communication Strategies: Psycholinguistic and Sociolinguistic Perspectives. Hoboken: Taylor and Francis.

Kathlene, L., \& Martin, J. A. (1991). Enhancing Citizen Participation: Panel Designs, Perspectives, and Policy Formation.

Keiser, L. R. (2010). Understanding Street-Level Bureaucrats’ Decision Making: Determining Eligibility in the Social Security Disability Program.

Kickbusch, I., \& Maag, D. (2008). Health Literacy (K. Heggenhougen, Ed.). Amsterdam: Elsevier, Acad. Press. 
Knibbe, M., Vries, M., \& Horstman, K. (2016). Responsible use of media supports "critical public health literacy." https://doi.org/10.1093/pubmed/fdw036

Kristensen, N., Andersen, L. B., \& Pedersen, L. H. (2012). Public Service Efficacy.

Lim, H.-H. (2006). Representative Bureaucracy: Rethinking Substantive Effects and Active Representation.

Lipsky, M. (2010). Street-Level Bureaucracy: Dilemmas of the Individual in Public Service. New York: Russell Sage Foundation.

Ludwig-Mayerhofer, W., Behrend, O., \& Sondermann, A. (2014). Activation, Public Employment Services and their Clients: The Role of Social Class in a Continental Welfare State.

Mancuso, J. M. (2010). Impact of health literacy and patient trust on glycemic control in an urban USA population. Nursing \& Health Sciences, 12, 94-104.

Manganello, J. A. (2008). Health literacy and adolescents: A framework and agenda for future research.

Maynard-Moody, S., \& Musheno, M. (2012). Social Equities and Inequities in Practice: Street-Level Workers as Agents and Pragmatists. Wiley Subscription Services, Inc.

Meier, K. J., \& Nicholson-Crotty, J. (2006). Gender, Representative Bureaucracy, and Law Enforcement: The Case of Sexual Assault. [American Society for Public Administration, Wiley].

Moynihan, D., Herd, P., \& Harvey, H. (2014). Administrative Burden: Learning, Psychological, and Compliance Costs in Citizen-State Interactions.

Nicholson-Crotty, S., Nicholson-Crotty, J., \& Fernandez, S. (2017). Will More Black Cops Matter? Officer Race and Police-Involved Homicides of Black Citizens. 
Nisar, M. A. (2018). Children of a Lesser God: Administrative Burden and Social Equity in Citizen-State Interactions.

Nutbeam, D. (2000). Health literacy as a public health goal: A challenge for contemporary health education and communication strategies into the $21 \mathrm{st}$ century.

Nutbeam, D. (2009). Defining and measuring health literacy: What can we learn from literacy studies?

Osborne, J. W., \& Fitzpatrick, D. C. (2012). Replication Analysis in Exploratory Factor Analysis: What it is and why it makes your analysis better.

Osborne, R. H., Batterham, R. W., Elsworth, G. R., Hawkins, M., \& Buchbinder, R. (2013). The grounded psychometric development and initial validation of the Health Literacy Questionnaire (HLQ). BMC Public Health, 13, 658.

Ozer, E. M., \& Bandura, A. (1990). Mechanisms governing empowerment effects: A self-efficacy analysis.

Paasche-Orlow, M. K., \& Wolf, M. S. (2007). The causal pathways linking health literacy to health outcomes.

Parrado, S., van Ryzin, G. G., Bovaird, T., \& Löffler, E. (2013). Correlates of Coproduction: Evidence From a Five-Nation Survey of Citizens.

Pornprasertmanit, S., Miller, P., Schoemann, A., \& Rosseel, Y. (2016). semTools: Useful tools for structural equation modeling.

Raaphorst, N., \& Loyens, K. (2018). From Poker Games to Kitchen Tables: How Social Dynamics Affect Frontline Decision Making.

Raaphorst, N., \& van de Walle, S. (2018). A signaling perspective on bureaucratic encounters: How public officials interpret signals and cues: How public officials interpret signals and cues. 
Reddick, C. G., \& Turner, M. (2012). Channel choice and public service delivery in Canada: Comparing e-government to traditional service delivery.

Redish, J. (1983). The language of bureaucracy (R. W. Bailey \& R. M. Fosheim, Eds.). New York: Modern Language Association of America.

Revelle, W. (2017). psych: Procedures for personality and Psychological Research. Evanston,, IL: Northwestern University.

Riccucci, N. M., van Ryzin, G. G., \& Li, H. (2016). Representative Bureaucracy and the Willingness to Coproduce: An Experimental Study.

Rikard, R. V., Thompson, M. S., McKinney, J., \& Beauchamp, A. (2016). Examining health literacy disparities in the United States: A third look at the National Assessment of Adult Literacy (NAAL). BMC Public Health, 16, 975.

Rossel, Y. (2017). Lavaan: An R package for structural equation and more.

Sarangi, S., \& Slembrouck, S. (1996). Language, bureaucracy, and social control. London; New York: Longman.

Schwarzer, R. (2014). Self-Efficacy: Thought Control Of Action. Hoboken: Taylor and Francis.

Selden, C. R., Zorn, M., Ratzan, S. C., \& Parker, R. M. (2000). Health Literacy [UnpublishedWork].

Senghaas, M., Freier, C., \& Kupka, P. (2019). Practices of activation in frontline interactions: Coercion, persuasion, and the role of trust in activation policies in Germany. Wiley/Blackwell (10.1111).

Sorensen, K., van den Broucke, S., Fullam, J., Doyle, G., Pelikan, J., Slonska, Z., \& Brand, H. (2012). Health literacy and public health: A systematic review and integration of definitions and models. 
Soss, J. (1999). Welfare Application Encounters: Subordination, Satisfaction, and the Puzzle of Client Evaluations. Administration \& Society, 31, 50-94.

Strecher, V. J., DeVellis, B. M., Becker, M. H., \& Rosenstock, I. M. (1986). The role of self-efficacy in achieving health behavior change.

Thiel, H., \& Thomsen, S. L. (2013). Noncognitive skills in economics: Models, measurement, and empirical evidence. Research in Economics, 67, 189-214.

Tiu Wright, L., Ouschan, R., Sweeney, J., \& Johnson, L. (2006). Customer empowerment and relationship outcomes in healthcare consultations.

van Eijk, C., \& Steen, T. (2016). Why engage in co-production of public services?: Mixing theory and empirical evidence.

Vrieze, S. I. (2012). Model selection and psychological theory: A discussion of the differences between the Akaike information criterion (AIC) and the Bayesian information criterion (BIC).

Wallin Andreassen, T. (1994). Satisfaction, Loyalty and Reputation as Indicators of Customer Orientation in the Public Sector.

Weber, L. M., Loumakis, A., \& Bergman, J. (2003). Who Participates and Why?

Zarcadoolas, C. (2005). Understanding health literacy: An expanded model. 
Figure 1: Different levels of effects

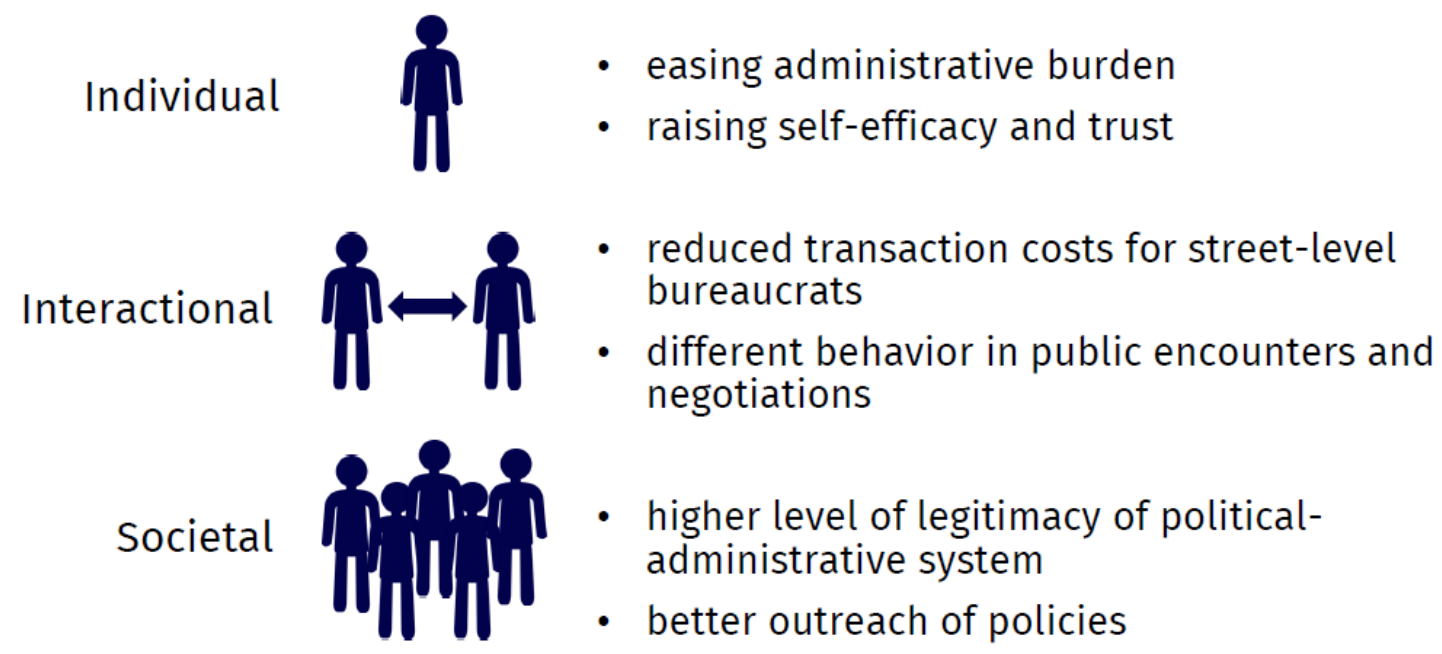


Table 1: Subdimensions of Administrative Literacy

\begin{tabular}{|c|c|c|c|c|}
\hline Dimension & Definition & Example & Sample item & Reference \\
\hline $\begin{array}{l}\text { Functional } \\
\text { Literacy }\end{array}$ & $\begin{array}{l}\text { basic skills in reading and } \\
\text { writing }\end{array}$ & $\begin{array}{l}\text { Understanding forms and } \\
\text { official letters }\end{array}$ & $\begin{array}{l}\text { It's easy for me } \\
\text { to read complex } \\
\text { texts with } \\
\text { multi-clause } \\
\text { sentences. }\end{array}$ & $\begin{array}{l}\text { Nutbeam } \\
(2000)\end{array}$ \\
\hline $\begin{array}{l}\text { Communicative } \\
\text { Literacy }\end{array}$ & $\begin{array}{l}\text { advanced cognitive skills } \\
\text { which, can be used to } \\
\text { actively participate in } \\
\text { everyday activities, to } \\
\text { extract and exchange } \\
\text { information, and derive } \\
\text { meaning from different } \\
\text { forms of communication }\end{array}$ & $\begin{array}{l}\text { - Comprehending demands } \\
\text { from public employees } \\
\text { - Explaining personal needs } \\
\text { and reasons }\end{array}$ & $\begin{array}{l}\text { It's easy for me } \\
\text { to communicate } \\
\text { with other } \\
\text { people. }\end{array}$ & $\begin{array}{l}\text { Nutbeam } \\
\text { (2000); } \\
\text { Osborne et al. } \\
\text { (2013) }\end{array}$ \\
\hline $\begin{array}{l}\text { Structural } \\
\text { Literacy }\end{array}$ & $\begin{array}{l}\text { skills to navigate the } \\
\text { administrative system, by } \\
\text { knowing relevant actors, } \\
\text { their responsibilities, and } \\
\text { available resources }\end{array}$ & $\begin{array}{l}\text { - Knowing the correct } \\
\text { contact to address when } \\
\text { applying for services } \\
\text { - Understanding division of } \\
\text { labor in bureaucracies and } \\
\text { its consequences for } \\
\text { processing }\end{array}$ & $\begin{array}{l}\text { I know the } \\
\text { purpose of } \\
\text { different public } \\
\text { organizations } \\
\text { for citizens. }\end{array}$ & $\begin{array}{l}\text { Grönlund et } \\
\text { al. (2007); } \\
\text { Osborne et al. } \\
\text { (2013) }\end{array}$ \\
\hline $\begin{array}{l}\text { Processual } \\
\text { Literacy }\end{array}$ & $\begin{array}{l}\text { skills to interact } \\
\text { appropriately during } \\
\text { public encounters due to } \\
\text { knowledge about one's } \\
\text { role in bureaucratic } \\
\text { processes and routines }\end{array}$ & $\begin{array}{l}\text { Behaving in a way } \\
\text { expected by public } \\
\text { employees to achieve } \\
\text { favorable outcomes } \\
\text { - Understanding } \\
\text { nonpersonal addresses } \\
\text { and necessities of certain } \\
\text { control processes }\end{array}$ & $\begin{array}{l}\text { Public } \\
\text { organizations } \\
\text { rely on } \\
\text { standardized } \\
\text { letters and } \\
\text { processes. }\end{array}$ & $\begin{array}{l}\text { Grönlund et } \\
\text { al. (2007) }\end{array}$ \\
\hline Media Literacy & $\begin{array}{l}\text { skills to search, process, } \\
\text { and critically evaluate } \\
\text { information from various } \\
\text { sources }\end{array}$ & $\begin{array}{l}\text { Researching information } \\
\text { on policy programs } \\
\text { Finding out which } \\
\text { documents to produce } \\
\text { when applying for services }\end{array}$ & $\begin{array}{l}\text { I inform myself } \\
\text { on a regular } \\
\text { basis through } \\
\text { media (print / } \\
\text { digital news or } \\
\text { newspaper) }\end{array}$ & $\begin{array}{l}\text { Knibbe et al. } \\
\text { (2016), } \\
\text { Osborne et al. } \\
\text { (2013) }\end{array}$ \\
\hline
\end{tabular}


Table 2: Comparison of first- and second-order models

\begin{tabular}{lcc} 
criteria & first-order model & second-order model \\
CFI & 0.941 & 0.929 \\
RMSEA & 0.067 & 0.072 \\
AIC & 18800.309 & 18844.394 \\
BIC & 18985.663 & 19008.685 \\
\hline
\end{tabular}


Table 3: Internal construct validity

\begin{tabular}{lllllll}
\hline & 1 & 2 & 3 & 4 & 5 \\
\hline $\mathbf{1}$ & Communicative Literacy & 0.88 & & & & \\
$\mathbf{2}$ & Processual Literacy & $0.310^{* * *}$ & 0.75 & & & \\
$\mathbf{3}$ & Structural Literacy & $0.281^{* * *}$ & $0.139^{*}$ & 0.83 & & \\
4 & Functional Literacy & $0.240^{* * *}$ & -0.085 & $0.431^{* * *}$ & 0.92 & \\
5 & Media Literacy & $0.361^{* * *}$ & $0.210^{* * *}$ & $0.285^{* * *}$ & $0.205^{* * *}$ & 0.80 \\
\hline
\end{tabular}

${ }_{\mathrm{p}}^{*}<0.05 ;{ }^{* *} \mathrm{p}<0.01 ;{ }^{* * *} \mathrm{p}<0.001$; diagonal contains McDonald's omega 
Table 4: Convergent and discriminant validity

\begin{tabular}{lccccc}
\hline & $\begin{array}{r}\text { Communicative } \\
\text { Literacy }\end{array}$ & $\begin{array}{r}\text { Processual } \\
\text { Literacy }\end{array}$ & $\begin{array}{r}\text { Structural } \\
\text { Literacy }\end{array}$ & $\begin{array}{r}\text { Functional } \\
\text { Literacy }\end{array}$ & $\begin{array}{r}\text { Media } \\
\text { Literacy }\end{array}$ \\
\hline self-efficacy & $0.193^{* *}$ & 0.013 & $0.313^{* * *}$ & $0.348^{* * *}$ & 0.032 \\
speaking2employee & $0.596^{* * *}$ & -0.116 & 0.120 & $0.160^{* *}$ & $0.106^{*}$ \\
Deadlines & $0.284^{* * *}$ & $0.348^{* *}$ & 0.065 & -0.037 & $0.095^{*}$ \\
satisfaction & 0.118 & $-0.552^{* * *}$ & $0.260^{*}$ & 0.031 & $0.113^{*}$ \\
Male & -0.027 & -0.002 & 0.057 & -0.002 & 0.041 \\
public sector & -0.046 & -0.005 & 0.085 & -0.007 & -0.104 \\
Education & 0.066 & -0.063 & -0.058 & $0.158^{* *}$ & $0.095^{*}$ \\
\hline Standardized beta coefficients from SEM are reported & & & & \\
$* \mathrm{p}<0.05 ; * * \mathrm{p}<0.01 ; * * * \mathrm{p}<0.001$ & & & & &
\end{tabular}




\section{Appendix}

Table 5: Factor loadings on seven literacy dimensions with 27-item pool

\begin{tabular}{|c|c|c|c|c|c|c|c|c|c|c|}
\hline Variable & PA4 & PA2 & PA3 & PA1 & PA5 & PA7 & PA6 & h2 & $\mathrm{u} 2$ & com \\
\hline 1 & & & & 0.67 & & & & 0.54 & 0.46 & 1.16 \\
\hline 2 & & & & 0.99 & & & & 0.73 & 0.27 & 1.12 \\
\hline 3 & & & & 0.90 & & & & 0.70 & 0.30 & \\
\hline 4 & & 0.70 & & & & & & 0.55 & 0.45 & 1.18 \\
\hline 5 & & 0.69 & & & & & & 0.48 & 0.52 & 1.03 \\
\hline 6 & & 0.70 & & & & & & 0.53 & 0.47 & 1.16 \\
\hline 7 & & 0.73 & & & & & & 0.50 & 0.50 & 1.17 \\
\hline 8 & & 0.64 & & & & & & 0.40 & 0.60 & 1.29 \\
\hline 9 & & 0.55 & & & & -0.44 & & 0.37 & 0.63 & 2.17 \\
\hline 10 & & & & 0.37 & & 0.45 & & 0.49 & 0.51 & 2.09 \\
\hline 11 & & & & & 0.33 & & & 0.41 & 0.59 & 3.53 \\
\hline 12 & & & & & & 0.38 & & 0.67 & 0.33 & 3.48 \\
\hline 13 & & & & & & 0.59 & & 0.48 & 0.52 & 1.49 \\
\hline 14 & & & & & & 0.54 & & 0.37 & 0.63 & 1.60 \\
\hline 15 & & & 0.87 & & & & & 0.75 & 0.25 & 1.02 \\
\hline 16 & & & 0.92 & & & & & 0.78 & 0.22 & 1.06 \\
\hline 17 & & & 0.59 & & & & & 0.54 & 0.46 & 1.16 \\
\hline 18 & & & 0.54 & & & & & 0.46 & 0.54 & 1.44 \\
\hline 19 & & & 0.60 & & & & & 0.51 & 0.49 & 1.25 \\
\hline 20 & 0.97 & & & & & & & 0.81 & 0.19 & 1.08 \\
\hline 21 & 0.96 & & & & & & & 0.84 & 0.16 & 1.03 \\
\hline 22 & 0.94 & & & & & & & 0.76 & 0.24 & 1.07 \\
\hline 23 & & & & & 0.70 & & & 0.43 & 0.57 & 1.21 \\
\hline 24 & & & & & 1.01 & & & 0.80 & 0.20 & 1.12 \\
\hline 25 & & & & & & & 0.35 & 0.19 & 0.81 & 1.65 \\
\hline 26 & & & & & & & 0.88 & 0.83 & 0.17 & 1.18 \\
\hline 27 & & & & & & & & 0.19 & 0.81 & 1.93 \\
\hline Eigenvalues & 2.82 & 2.83 & 2.87 & 2.54 & 1.51 & 1.58 & 0.98 & & & \\
\hline PA4 & 1.00 & 0.06 & 0.27 & 0.55 & 0.51 & 0.46 & 0.10 & & & \\
\hline PA2 & 0.06 & 1.00 & 0.41 & 0.25 & 0.32 & 0.28 & 0.20 & & & \\
\hline PA3 & 0.27 & 0.41 & 1.00 & 0.31 & 0.37 & 0.51 & 0.34 & & & \\
\hline PA1 & 0.55 & 0.25 & 0.31 & 1.00 & 0.51 & 0.48 & 0.15 & & & \\
\hline PA5 & 0.51 & 0.32 & 0.37 & 0.51 & 1.00 & 0.44 & 0.29 & & & \\
\hline PA7 & 0.46 & 0.28 & 0.51 & 0.48 & 0.44 & 1.00 & 0.14 & & & \\
\hline PA6 & 0.10 & 0.20 & 0.34 & 0.15 & 0.29 & 0.14 & 1.00 & & & \\
\hline
\end{tabular}

rotation $=$ Promax; loadings below 0.3 are not displayed 
Figure 2: Parallel analysis of 17 -item pool

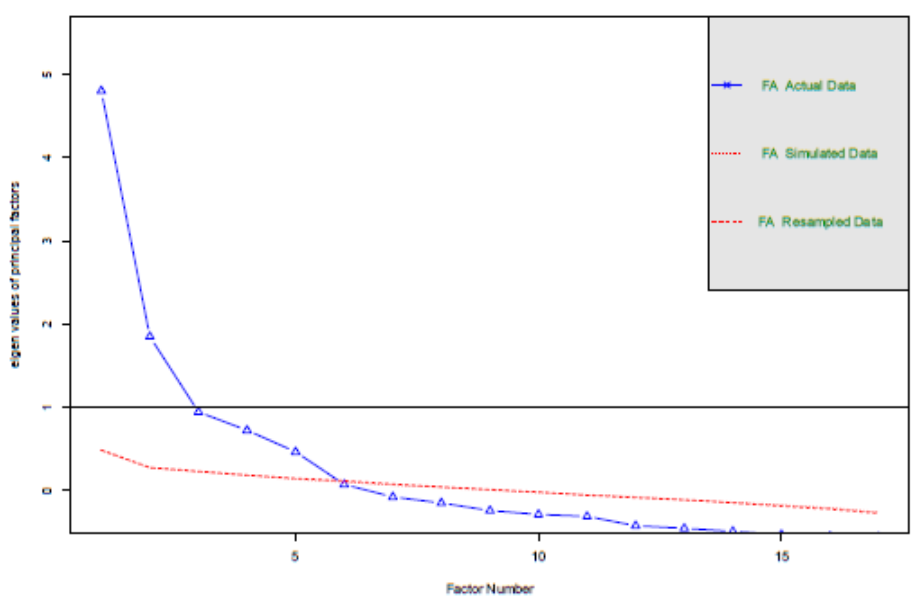


Table 6: Factor loadings for five literacy dimensions with 17-item pool

\begin{tabular}{lcccccccc}
\hline Variable & PA1 & PA2 & PA3 & PA4 & PA5 & h2 & u2 & com \\
\hline 1 & & & $\mathbf{0 . 6 4}$ & & & 0.50 & 0.50 & 1.03 \\
2 & & & $\mathbf{0 . 9 1}$ & & & 0.74 & 0.26 & 1.03 \\
3 & & & $\mathbf{0 . 8 7}$ & & & 0.74 & 0.26 & 1.01 \\
4 & & $\mathbf{0 . 6 4}$ & & & & 0.46 & 0.54 & 1.06 \\
5 & & $\mathbf{0 . 6 7}$ & & & & 0.45 & 0.55 & 1.06 \\
6 & & $\mathbf{0 . 7 6}$ & & & & 0.60 & 0.40 & 1.04 \\
7 & & $\mathbf{0 . 8 1}$ & & & & 0.60 & 0.40 & 1.04 \\
8 & $\mathbf{0 . 9 3}$ & & & & & 0.76 & 0.24 & 1.02 \\
9 & $\mathbf{0 . 9 2}$ & & & & & 0.75 & 0.25 & 1.02 \\
10 & $\mathbf{0 . 6 7}$ & & & & & 0.54 & 0.46 & 1.05 \\
11 & $\mathbf{0 . 6 7}$ & & & & & 0.46 & 0.54 & 1.13 \\
12 & $\mathbf{0 . 5 9}$ & & & & & 0.51 & 0.49 & 1.12 \\
13 & & & & $\mathbf{0 . 8 9}$ & & 0.81 & 0.19 & 1.03 \\
14 & & & & $\mathbf{0 . 9 1}$ & & 0.86 & 0.14 & 1.03 \\
15 & & & & $\mathbf{0 . 8 9}$ & & 0.75 & 0.25 & 1.01 \\
16 & & & & & $\mathbf{0 . 8 3}$ & 0.66 & 0.34 & 1.02 \\
17 & & & & & $\mathbf{0 . 7 4}$ & 0.55 & 0.45 & 1.01 \\
\hline Eigenvalue & 2.96 & 2.1 & 1.99 & 2.46 & 1.23 & & & \\
\hline & & & & & & & & \\
PA1 & 1.00 & 0.45 & 0.43 & 0.35 & 0.42 & & & \\
PA2 & 0.45 & 1.00 & 0.25 & 0.05 & 0.20 & & & \\
PA3 & 0.43 & 0.25 & 1.00 & 0.41 & 0.30 & & & \\
PA4 & 0.35 & 0.05 & 0.41 & 1.00 & 0.34 & & & \\
PA5 & 0.42 & 0.20 & 0.30 & 0.34 & 1.00 & & & \\
\hline
\end{tabular}

rotation = Promax; loadings below 0.4 are not displayed

PA1 = Communicative Literacy, PA2 = Processual Literacy, PA3 = Structural Literacy, PA4 $=$ Functional Literacy, PA5 $=$ Media Literacy 
Table 7: Descriptive statistics

\begin{tabular}{lccccc}
\hline \hline Statistic & $\mathrm{N}$ & Mean & St. Dev. & Min & Max \\
\hline PA1(1) & 1,017 & 4.129 & 0.874 & 1 & 5 \\
PA1(2) & 1,017 & 4.132 & 0.871 & 1 & 5 \\
PA1(3) & 1,017 & 4.221 & 0.856 & 1 & 5 \\
PA1(4) & 1,017 & 4.280 & 0.803 & 1 & 5 \\
PA1(5) & 1,016 & 3.939 & 0.908 & 1 & 5 \\
PA2(1) & 1,020 & 4.221 & 0.796 & 1 & 5 \\
PA2(2) & 1,020 & 4.125 & 0.841 & 1 & 5 \\
PA2(3) & 1,020 & 4.269 & 0.793 & 1 & 5 \\
PA2(4) & 1,020 & 4.210 & 0.827 & 1 & 5 \\
PA3(1) & 1,020 & 3.446 & 0.932 & 1 & 5 \\
PA3(2) & 1,020 & 3.125 & 1.010 & 1 & 5 \\
PA3(3) & 1,020 & 3.358 & 0.973 & 1 & 5 \\
PA4(1) & 1,017 & 3.041 & 1.128 & 1 & 5 \\
PA4(2) & 1,017 & 2.858 & 1.128 & 1 & 5 \\
PA4(3) & 1,017 & 3.125 & 1.140 & 1 & 5 \\
PA5(1) & 1,014 & 3.744 & 1.088 & 1 & 5 \\
PA5(2) & 1,014 & 3.366 & 1.107 & 1 & 5 \\
selfeff(1) & 1,043 & 4.031 & 0.971 & 1 & 5 \\
selfeff(2) & 1,043 & 3.649 & 1.040 & 1 & 5 \\
selfeff(3) & 1,043 & 3.409 & 1.004 & 1 & 5 \\
selfeff(4) & 1,042 & 3.722 & 0.947 & 1 & 5 \\
selfeff(5) & 1,043 & 3.865 & 1.064 & 1 & 5 \\
male & 991 & 1.476 & 0.500 & 1 & 2 \\
education & 995 & 1.930 & 0.825 & 1 & 3 \\
deadlines & 1,020 & 4.349 & 0.796 & 1 & 5 \\
speak2employee & 1,014 & 3.835 & 0.910 & 1 & 5 \\
public & 688 & 0.206 & 0.405 & 0 & 1 \\
\hline & & & & &
\end{tabular}




\section{Table 8: Item descriptions}

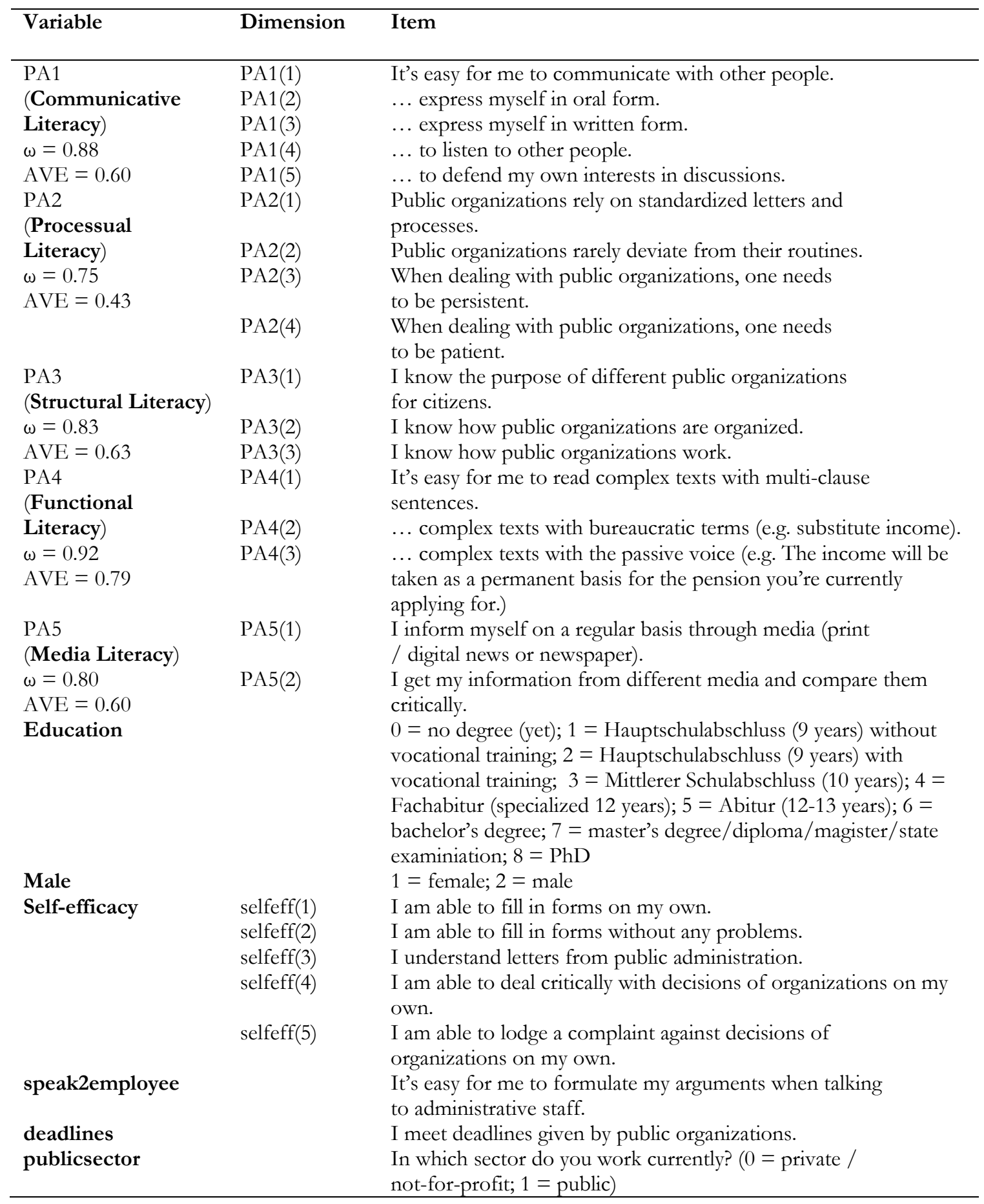

